\title{
Many Family Medicine Successful Interventions and Clinical Reviews for Common Illnesses
}

\author{
Marjorie A. Bowman, MD, MPA, Anne Victoria Neale, PhD, MPH, and \\ Dean A. Seebusen, MD, MPH
}

Family physician researchers continue to provide assistance to improve family medicine care.

Commentaries on social determinants of health lead off this issue. Next, we have several papers on successful interventions by clinicians and/or patients to improve diabetes control, and then other provide information on other practice interventions that make a difference in overall care. Drug advertising continues to mislead. There is costly and nonproductive overuse of specific types of care. Herein is also a Scoping Review of possible indices for determining timely initiation of advance care planning. The issue's clinical reviews on use of transgender care, cervical myelopathy, and inhaled steroids for chronic obstructive pulmonary disease are pertinent, thorough, and timely. ( $\mathrm{J}$ Am Board Fam Med 2020;33:161-163.)

\section{Screening for Social Determinants of Health}

We have 2 commentaries related to screening for social determinants of health $(\mathrm{SDH}) .{ }^{1-3}$ We know that multiple social determinants affect health, and there has been a strong move toward SDH screening in health settings. But do patients want SDH screening? Should "fixing" the SDH be the work for individuals, from a small but dedicated group such as an individual practice, or does it take a whole society to impact SDH? ${ }^{4}$ Read the commentaries that go into depth on the subject.

\section{Improving Diabetes Care and Prevention}

Here is an amazing success story: Figueroa et $\mathrm{al}^{5}$ reported that 7 family medicine residency programs used systematic prenatal counseling for $>1500$ patients, leading to lower pregnancy weight gain and a reduced incidence of prenatal diabetes! This success resulted from providers implementing the recommendations of the National Academy of Medicine (previously named the Institute of Medicine).

Some may not be familiar with "psychological insulin resistance," a term used when a patient is psychologically opposed to initiating insulin. Many clinicians will be familiar with patients who resist starting insulin therapy. I (MB) once had a patient

Conflict of interest: The authors are editors of the $7 A B F M$. with very high hemoglobin A1c values associated with adult onset diabetes who repeatedly refused insulin because he so feared injections (in spite of office demonstrations). There was a solution: with his permission, his wife gave him the insulin while he was asleep. By the next visit, he was giving himself the injections and said, "Well, I never woke up when she gave me the shots and my sugars were better." Tanga et $\mathrm{al}^{6}$ reported on additional physician strategies that did and did not work to overcome psychological insulin resistance.

Careyva et $\mathrm{al}^{7}$ specified the methodology for creating a prediabetes shared decision aid that both patients and physicians found helpful. See the 2page visual decision aid in the appendix. Thankfully, the involved physicians also did not believe it prolonged visits. In a qualitative study from the Military Primary Care Research Network, Ledford et $\mathrm{al}^{8}$ identified various turning points for patients with type 2 diabetes, examining how patients make needed changes.

\section{Improving Patient Outcomes}

In another success story, Davis et $\mathrm{al}^{9}$ showed the advantage of repeated attempts to improve care with various interventions rolled out over time. This case study is from a single practice that monitored their outcomes over time as they successively implemented home visits, same-day urgent care, more care coordination, and in-office laboratory blood 
draws. The numbers show impressive success, with the same-day urgent care appearing to have made the most difference in lowering hospitalization rates. Jiang et $\mathrm{al}^{10}$ considered the various influences on preventive service guideline uptake and found a complex interplay of factors, including the patient, clinicians, the practice, the health system, the environment, and the guidelines themselves. Sweeney et $\mathrm{al}^{11}$ reported on a project using practice facilitation for quality improvement. The Agency for Healthcare Research and Quality funded 7 Cooperatives, each of which worked with over 200 primary care practices to rapidly disseminate and implement multiple targeted improvements in cardiovascular preventive care. Much has been learned from this large project, but a specific learning point is that it takes substantial infrastructure and dedicated staff to create significant and sustainable practice change.

\section{Drug Advertising}

Few physicians will be surprised by the study results reported by Jung and Fugh-Berman ${ }^{12}$ : in spite of Food and Drug Administration rules, many of the marketing messages found in continuing medical education materials for binge eating disorder are disconcerting and do not follow the rules. Sullivan et $\mathrm{al}^{13}$ also found that patients are influenced by advertising. This interesting report of a nationwide FDA survey investigated patient responses to drug company direct-to-consumer advertising. Although many people would ask a physician for a specific medication brand, a sizeable minority would change clinicians if their request was refused.

\section{Overuse Related to Endocrinology Issues}

Rozario et $\mathrm{al}^{14}$ successfully intervened to decrease the overuse of vitamin D screening through primary care clinician education plus electronic health record interventions, saving 1 healthcare system more than 1 million dollars. Thyroid hormone use in the United States has skyrocketed, ${ }^{15}$ with expenditures tripling. The authors' explanation is enlightening.

\section{Review Articles}

This issue includes 3 informative clinical reviews. Kaplan ${ }^{16}$ addressed when to use, or to attempt withdrawal of, inhaled steroids for chronic obstructive pulmonary disease. McCormick et $\mathrm{al}^{17}$ reviewed cervical spondylotic myelopathy, including many hints and pictures on physical examination methods to assist with diagnosis. With an increasing recognition of the needs of transgender patients, Radix ${ }^{18}$ provided much clinical information and practice management tips to support clinician care. In addition, Kim et $\mathrm{al}^{19}$ provided a scoping review on advance care planning prognostic indices with potential use in primary care for determining whom should receive advance care planning discussions.

\section{Personal Reflections}

"Crashing Out of a Career" ${ }^{20}$ is a heartfelt reflection on an unexpected career at an Indian Health Service site, with illness eventually creating an early retirement. This essay will resonate with many clinicians who have established relationships with patients.

To see this article online, please go to: http://jabfm.org/content/33/ 2/161.full.

\section{References}

1. De Marchis EH, Alderwick H, Gottlieb LM. Do patients want help addressing social risks? J Am Board Fam Med 2020;33:170-175.

2. DeVoe JE. When and how do we need permission to help patients address social risk? J Am Board Fam Med 2020;33:176-178.

3. Khanna N. Complexities in integrating social risk assessment into health care delivery. J Am Board Fam Med 2020;33:179-181.

4. Silverstein M, Hsu HE, Bell A. Addressing social determinants to improve population health-the balance between clinical care and public health. JAMA 2019;322:2379-2380.

5. Figueroa EM, Nitti K, Sladek SM. Lowering gestational diabetes risk by prenatal weight gain counseling. J Am Board Fam Med 2020;33:189-197.

6. Tanga T, Hesslerb D, Polonsky WH, et al. Successful health care provider strategies to overcome psychological insulin resistance in United States and Canada. J Am Board Fam Med 2020;33:198-210.

7. Careyva BA, Shaak K, Burgess NM, et al. Designing and evaluating a prediabetes shared decision aid. J Am Board Fam Med 2020;33:262-270.

8. Ledford CJW, Fisher CL, Cafferty LA, Jackson JT, Seehusen DA, Crawford PF. Turning points as opportunities to partner with patients living with type 2 diabetes or prediabetes. J Am Board Fam Med 2020;33:211-219.

9. Davis T, Beste J, Batish S, Watford R, Farrell S. Eliminating patient identified barriers to decrease 
Medicaid inpatient admission rates and improve quality of care. J Am Board Fam Med 2020;33: 220-229.

10. Jiang V, Brooks EM, Tong ST, Heintzman J, Krist AH. Factors influencing uptake of changes to clinical preventive guidelines. J Am Board Fam Med 2020;33:271-278.

11. Sweeney SM, Hemler JR, Baron AN, et al. Dedicated workforce required to support largescale practice improvement. J Am Board Fam Med 2020;33:230-239.

12. Jung J, Fugh-Berman A. Marketing messages in continuing medical education (CME) modules on binge-eating disorder (BED). J Am Board Fam Med 2020;33:240-251.

13. Sullivan HW, Aikin KJ, Berktold J, Stein KL, Hoverman VJ. Direct-to-consumer prescription drug advertising and patient-provider interactions. J Am Board Fam Med 2020;33:279-283.

14. Rozario NL, Sparling A, Burns R, et al. Modifying provider vitamin $\mathrm{D}$ screening behavior in primary care. J Am Board Fam Med 2020;33: 252-261.

15. Johansen ME, Marcinek JP, Yun J. Thyroid hormone use in the United States, 1997-2016. J Am Board Fam Med 2020;33:284-288.

16. Kaplan AG. Inhaled corticosteroid treatment in chronic obstructive pulmonary disease (COPD): boon or bane? J Am Board Fam Med 2020;33:289-302.

17. McCormick JR, Sama AJ, Schiller NC, Butler AJ, Donnally CJ, III., Cervical spondylotic myelopathy: a guide to diagnosis and management. J Am Board Fam Med 2020;33:303-313.

18. Radix AE. Addressing needs of transgender patients: the role of family physicians. J Am Board Fam Med 2020;33:314-321.

19. Kim P, Daly JM, Berry-Stoelzle MA, et al. Prognostic Indices for advance care planning in primary care: a scoping review. J Am Board Fam Med 2020;33:322-338.

20. Neufeld B. Crashing out of a career. J Am Board Fam Med 2020;33:339-341. 